\title{
Bourdieu y lo político
}

\author{
Gabriela Albanás Couto" \\ Universidade Federal de Santa Catarina, Doutoranda em Educação \\ Schirlei Russi Uon Dentz ${ }^{2}$ \\ Universidade Federal de Santa Catarina, Doutoranda em Educação
}

\begin{abstract}
Ione Ribeiro Ualle ${ }^{3}$
Universidade Federal de Santa Catarina, Professora, bolsista de produtividade em pesquisa CNPq nível 1D
\end{abstract}

GAMBAROTTA, Emiliano. Bourdieu y lo político. Buenos Aires: Prometeo Libros, 2016. 310 p.

Bourdieu y lo político, ${ }^{4}$ livro de 2016 publicado na Argentina por Emiliano Gambarotta, ${ }^{5}$ tem como principal argumento a centralidade da questão do "político" na teoria social produzida por Pierre Bourdieu (1930-2002). A dominação social, seus mecanismos e como estes produzem e reproduzem as (e nas) práticas sociais é seu foco principal de análise. A opção por centrar-se no "político", afirma o autor, deve-se ao fato de considerá-lo chave de leitura para toda a teoria bourdieusiana, argumento que ele explora de maneira instigante ao longo da obra. Para Gambarotta, pensando com Bourdieu, a dominação ocorre nas práticas sociais por uma espécie de "alquimia simbólica"; nela a educação ocupa um papel fundamental. É com o objetivo de apontar a centralidade da questão da dominação na sociologia bourdieusiana que o autor retoma suas categorias fundamentais, a saber, o nomos, que diz respeito às práticas sociais, e a doxa, que estaria na dimensão do simbólico, buscando mostrar ao leitor o movimento dialético entre as instâncias nomos/objetivo/práticas e doxa/subjetivo/ simbólico, a partir do e atravessado pelo modo de pensar relacional característico de Pierre Bourdieu. Gambarotta, todavia, não se limita a mostrar os desvelamentos da realidade social que a teoria de Bourdieu produz, mas nos leva a pensar em possibilidades de rompimento da dominação, o que chama de "o disruptivo" da sociologia bourdieusiana.

Doutoranda na linha de Sociologia e História da Educação no Programa de Pós-Graduação em Educação da Universidade Federal de Santa Catarina; Mestre em Educação no Programa de Pós-Graduação em Educação da Universidade de São Paulo; https://orcid.org/0000-0002-6000-5634; http://lattes.cnpq.br/9918967454987628.

2 Doutoranda na linha de Sociologia e História da Educação no Programa de Pós-Graduação em Educação da Universidade Federal de Santa Catarina; Mestre em Educação no Programa de Pós-Graduação em Educação da Universidade Federal de Santa Catarina; https://orcid.org/0000-0002-0332-8517; http://lattes.cnpq.br/9797662752702698.

3 Pós-Doutora pela École des Hautes Études en Sciences Sociales - Paris; Doutora em Ciências da Educação pela Université René Descartes - Paris V Sorbonne; https://orcid.org/0000-0001-7496-3959; http://lattes.cnpq.br/4490226468776272.

4 Bourdieu e o político, obra não traduzida para o português, portanto, ainda inédita no Brasil.

5 Sociólogo argentino, tem se dedicado a trabalhar com "os fundamentos de uma teoria crítica da cultura política". A partir de uma perspectiva dialética, sob o mesmo prisma da Escola de Frankfurt, vem desenvolvendo pesquisas relacionadas à influência da obra de Merleau Ponty em Pierre Bourdieu. Em 2014 publicou Hacia una teoría crítica reflexiva: Max Horkheimer, Theodor W. Adorno y Pierre Bourdieu e em 2016, Bourdieu y lo político. 
Colocando Bourdieu em diálogo com diversos pensadores de correntes atuais, especialmente aquelas que o autor denomina "teorias pós" - pós-modernismo, pós-estruturalismo, etc. -, Gambarotta localiza a sociologia bourdieusiana no cenário do pensamento social atual, analisando e respondendo a críticas que Bourdieu recebe dessas variadas correntes de pensamento. Seguindo a construção de uma dinâmica dialética, Bourdieu desenvolve seus argumentos em torno de um questionamento que acompanha toda a obra: "como acontece a política?". Compreendendo política como sendo "(des)ordenamento social", ou seja, as estratégias de reprodução ou de ruptura do status quo, Gambarotta nos convida a refletir, a partir dos conceitos centrais da teoria bourdieusiana postos em relação, como a sociedade produz sua própria desordem e como é possível que se ordene a si mesma.

A obra é composta por cinco capítulos, mais um excursus - capítulo central que marca a transição entre os conceitos fundamentais postos em debate com teorias sociais contemporâneas de abordagem "pós" e os capítulos finais, nos quais o autor constrói sua argumentação principal, a da dominação social em face ao político -, além de um capítulo de conclusão. Assim, de acordo com o próprio autor, o livro foi organizado em torno de três eixos, a saber: 1) um esboço das características principais da perspectiva elaborada por Bourdieu, abordando os diferentes núcleos investigativos com os quais ele se ocupou ao longo de sua obra; 2) um enfoque mais específico em sua teoria da dominação social reconstruindo os vários elementos que the dão especificidade, uma vez demonstrada ser esta a preocupação central em sua sociologia; e 3) o esforço por esboçar uma teoria crítica reflexiva do político, em discussão com o pensamento "pós".

No capitulo inicial, Introdução: conceitos e estilo, Gambarotta visita o que chama de "princípios fundamentais da perspectiva bourdieusiana": campo e capital, agente, habitus e prática, illusio, nomos e doxa, nesta sequência agrupados. Esse capítulo serve tanto ao leitor iniciante na teoria bourdieusiana, que encontrará ali, de maneira relacional, as principais categorias teóricas de Bourdieu, quanto aos leitores mais familiarizados e conhecedores de sua obra, tratando-se, portanto, de uma inovadora leitura dessas categorias já consagradas na sociologia contemporânea. Para Gambarotta, tais categorias estão enraizadas em uma lógica pautada pela dialética reflexiva, em um movimento entre subjetivismo e objetivismo. Assim, ele procura nos mostrar de que forma Bourdieu rejeitou a divisão (artificial) entre os modos de conhecimento subjetivista e objetivista, propondo, em contrapartida, a "prática de um estilo de movimento dialético-reflexivo"; concepção presente no cerne de sua teoria social. Esse movimento dialético-reflexivo (o modus operandi de Bourdieu, segundo o autor) é apontado por Emiliano Gambarotta como herança da influência do filósofo Maurice MerleauPonty na teoria bourdieusiana.

0 capítulo dois, Para uma crítica corporal do político, enfoca a sociologia do corpo em Bourdieu e desenvolve uma discussão sobre o "pensamento pós", especificamente acerca 
de duas de suas vertentes: os estudos culturalistas do corpo e o pós-estruturalismo, especialmente em Judith Butler. Seu objetivo é delinear a noção de "modo de corporalidade" como núcleo de uma proposta que busca avançar para uma crítica corporal do político. Gambarotta argumenta que a produção da corporalidade tem seu lugar na conformação dos grupos e em sua diferenciação em relação aos demais e considera, a partir da leitura que faz de Bourdieu, o uso dos corpos como fator produtor de distinção, o que estaria na base da dominação social.

0 terceiro capítulo, Um materialismo cultural, é centrado na "sociologia da cultura" praticada por Bourdieu, fundamentada em uma lógica e em uma "economia das práticas". Seu objetivo é problematizar a função da cultura no político a partir da construção de uma perspectiva de crítica cultural. 0 autor justifica a relevância e a atualidade desse debate com o "pensamento pós", horizonte conceitual predominante neste início de século XXI, constituindose no Zeitgeist de nosso tempo, cuja consequência seria a dissolução da possibilidade da crítica. 0 autor, dessa forma, constrói sua própria crítica sobre as duas vertentes principais do pensamento pós, o culturalismo e o pós-estruturalismo.

Entre o terceiro e o quarto capítulo aparece o que Gambarotta denomina de excursus, ou seja, uma digressão pela sociologia da educação bourdieusiana, uma vez que esta é, segundo ele, fundamental tanto para a sociologia da cultura quanto para a sociologia política. 0 mérito herdado: a produção escolar de uma nobreza, título dado a este excursus, expõe alguns questionamentos que as chamadas teorias da resistência fazem à sociologia da educação bourdieusiana, especialmente a partir de Jacques Rancière. Gambarotta explica que, sendo a centralidade da obra de Bourdieu a realização de um pensamento dialético entre objetivismo e subjetivismo, efetuado por seu modo de pensar relacional, o sociólogo rejeita as concepções objetivistas que eliminam a autonomia do sistema de ensino - que funcionaria como mera engrenagem de um conjunto - e as subjetivistas, como se somente a origem social definisse o êxito escolar. Sob esse prisma, a contribuição da escola para a reprodução das desigualdades sociais se daria de forma dialética por meio de uma complexa trama de mediações, entre as quais Gambarotta destaca: a herança cultural, interpretada pela escola como elemento de distinção; a autoridade pedagógica, que legitima o arbitrário cultural; a taxonomia escolar, criadora de lógicas de classificação e de hierarquias entre os estudantes. Pierre Bourdieu desvelou a relação tida como natural que certos estudantes têm com o conhecimento e a rotina escolar, naturalizada como "aptidão" ou "dom" para os estudos, o que, na verdade, advém de uma herança familiar. A consequência disso, conforme destaca Gambarotta, é que "a herança (de capital cultural) põe grupos de estudantes em desiguais posições de partida no início de suas trajetórias educacionais. Lógica que, por sua vez, faz desses saberes e usos da cultura um capital." (GAMBAROTTA, 2016, p. 171, grifo do autor). Esse argumento vai ao encontro da tese central da obra Os herdeiros, de Pierre Bourdieu e 
Jean-Claude Passeron (1964), a de que "o sistema de educação, deve, entre outras funções, produzir sujeitos selecionados e hierarquizados de uma vez por todas e para toda a vida."

Gambarotta chama a atenção para a dialética entre o universal e o particular presente no que seria uma "pedagogia racional", ideia esboçada no último capítulo de Os herdeiros. 0 autor considera a dialética entre o universal e o particular na educação como eixo central dessa proposta e busca a partir daí desvelar a dominação presente no arbitrário cultural imposto pela escola; dominação esta que (re)produz desigualdades escolares e, por conseguinte, sociais. Para tanto, seguindo o pensamento de Bourdieu, propõe conhecer as leis de reprodução e de dominação social, a fim de que se tenha alguma possibilidade de minimizar a ação reprodutora da instituição escolar, entre elas a ideologia do dom, negação do processo social "da herança de um capital cultural e sua relação com o trabalho pedagógico familiar produtor de um habitus mais ou menos afim com o sistema de ensino" (GAMBAROTTA, 2016, p. 195). Tal processo conduz, na prática, a uma resignação e à legitimação da lógica da dominação, contribuindo, assim, para "a reprodução do político, ao fixar cada um em seu lugar através da despolitização que a naturalização inculca." (GAMBAROTTA, 2016, p. 196).

0 autor reconhece que, embora sejam questões próprias do âmbito educativo, por serem também sociais e, sobretudo, políticas, demandam saídas também políticas, que se desdobram em um desafio mais amplo: politizar a cultura política despolitizada e despolitizante. A partir desses pressupostos bourdieusianos, Gambarotta lança, então, os seguintes questionamentos: "como propor que o sistema de ensino não seja uma instância que contribui para a reprodução da desigual distribuição do capital cultural, mas, sim, de concretização da igualdade"? e "como a escola pode ser uma instância democratizadora?" (GAMBAROTTA, 2016, p. 196).

No quarto capítulo, Um estilo ilustrado: o lugar da ciência no político, o autor problematiza a relação entre o conhecimento sociológico e o político, com investimento maior nas obras de Bourdieu dedicadas à política, especialmente aquelas que fazem do Estado seu problema, de forma a complementar o estudo acerca da dominação, qualificada como "dominação simbólica". A reflexão questiona como a prática de produção de conhecimento sociológico, ou das ciências sociais em geral, "pode ser ela mesma uma prática disruptiva no político." (GAMBAROTTA, 2016, p. 201). A caracterização dos traços gerais da sociologia política de Bourdieu nos permitirá analisar o lugar que a sociologia se dá a si mesma nas lutas pelo político e aqui, novamente, faz-se possível realizar um diálogo com os questionamentos que Rancière dirige a Bourdieu e o desafio que eles nos lançam para pensar a crítica hoje. Lidar com esse desafio é o que nos conduzirá a propor um giro estético na concepção do simbólico, de acordo com o autor.

0 capítulo cinco, (Des)politização e democracia: sobre a prática disruptiva do político, ocupa-se em discutir uma prática disruptiva do político, indagando, especialmente, aquela 
disrupção do estabelecido que será chamada de "democratização". Novamente, o pensamento de Rancière é posto em tensão com o de Bourdieu, tensão crucial para a problematização do conceito de democracia. Esse capítulo é concluído com a ideia de que cabe denominar as questões técnicas e estéticas da democracia na maneira como a sociedade se ordena e desordena a si mesma. A democracia, afirma Gambarotta, é, nesse sentido, esse "estilo" de (des)ordenamento do social que acolhe a incerteza em seus próprios fundamentos.

Fechando a obra, Esboço de uma teoria crítica reflexiva do político, é dedicado à retomada das ideias principais debatidas nos capítulos anteriores, especialmente a defesa de uma leitura da obra bourdieusiana como sendo "uma vasta teoria da dominação, das práticas que a instituem e a alquimia simbólica em cuja mediação esta se produz." A partir dessa alquimia, o autor problematiza as lógicas simbólicas e as práticas sociais que podem levar a sua disrupção.

Ao mostrar que Bourdieu realiza um movimento dialético entre as duas instâncias - o subjetivo e o objetivo - não como simples "superação" ou supressão da relação subjetivo-objetivo, mas mantendo a diferença entre elas sem cindi-las em instâncias abstratas ou isoladas entre si, Gambarotta nos faz refletir acerca de como seria possível romper com práticas sociais de dominação a partir do plano simbólico, lembrando-nos que nele a educação tem total participação e relevância.

Recebida em 28 de fevereiro de 2019

Aceita em 1 de março de 2019

Publicada em 25 de abril de 2019

Endereços para correspondência: Rua da Capela, 219, Campeche, 88063-400, Florianópolis, Santa Catarina, Brasil; gabrielaacouto@gmail.com 
